\title{
GELATION OF DNA AND BOVINE SERUM ALBUMIN (DNA-BSA GEL) BY GAMMA IRRADIATION AS BIO-ABSORBENT FOR ACRIDINE ORANGE
}

\author{
H. Saito' ${ }^{1}$ TM. Quynh ${ }^{*}$, K. Furusawa ${ }^{3}$, N. Nagasawa4, T. Dobashi ${ }^{1}$ \\ ${ }^{1}$ Faculty of Science and Technology, Gunma University, Kiryu, Gunma, Japan \\ ${ }^{2}$ Hanoi Irradiation Center, Vietnam Atomic Energy Institute, Minh Khai, Tu Liem, Hanoi, Vietnam \\ 3Faculty of Advanced Life Science, Hokkaido University, Sapporo, Hokkaido, Japan \\ 4Japan Atomic Energy Agency, Quantum Beam Science Directorate, Takasaki, Gunma, Japan
}

\begin{abstract}
Together with their advantages, the availability of synthetic organic chemicals also caused many adverse effects to the environment due to the fact that they do not seem to be completely bio-degraded in nature. The residues of these synthetic organic compounds, such as polychlorinated biphenyl (PCBs), acridine orange (AO) and other aromatics, as well as their degraded intermediates, may become carcinogens or mutagens, which severely affect human health. In the cell, these organic compounds can intercalate into the major grooves and interstices between the base pair of DNA double helix, resulting in several diseases and cancers. In other words, DNA can be utilized as the most efficient bio-adsorbent of such toxic agents. For this purpose, DNA must be in water-insoluble state. Recently, radiation has been proven to be one of the effective methods of introducing the crosslinking network in the polymer matrix. Though DNA is easily broken by radiation, it can crosslink in the presence of suitable crosslinkers, or be immobilized onto the crosslinking gels. In this study, we have successfully prepared DNA/BSA complex gels from aqueous mixtures of DNA with BSA by gamma irradiation. Their gelation behaviors were characterized for utilization as adsorbents for AO. The results indicated that the adsorption was a time-dependent process and the adsorption capacity of AO increased with DNA amount in the DNA/BSA gels.
\end{abstract}

Key words: Gamma irradiation, DNA/BSA complex, gel fraction, swelling behavior, acridine orange, adsorption

DOI: $10.21175 / \operatorname{RadProc} .2016 .40$

\section{INTRODUCTION}

Nowadays, synthetic organic compounds have been widely used in various fields ranging from agriculture (plant protectors, preservative agents in foods), industry (lubricants, detergents, dyes) to medicine (antibiotics, drugs) due to their advantages compared with the same natural products. However, the abuse of synthetic organic compounds seriously contaminates the environment and causes critically health risks to people, because they seem not to be bio-degraded in nature after disposal and their residues easily penetrate and endanger living organisms [1]. At the body level, these cell deaths may increase the mutations and cancer risks by altering metabolism or damaging normal tissue. As a result, many organic aromatic compounds such as PCB, dioxin and dyes have been considered as mutagens or carcinogens [2-5].

Among those is acridine orange (AO), a cation dye that has been widely used in many areas. After it uptakes to the cell, it interacts with DNA and RNA molecules by intercalation or electrostatic attraction, modifies the DNA configuration and helix structure. Fortunately, this phenomenon can be applied in the other direction, to develop the absorbent materials for the carcinogen, because DNA can also attack and permanently entrap the carcinogen like aflatoxin, AO or other aromatics [6].

As mentioned in the previous report [7], DNA is an abundant polymer from agro-wastes or by-products of food processing. For example, there are 7\% DNA in 4000 tons of salmon sperm, which were annually discarded from Japan salmon industry; namely, about 300 tons of DNA can be extracted and reused [8]. According to the forecast, Vietnam's fish and seafood processing industry will produce about 50,000 tons of fish bones and waste in 2020 [9]; correspondingly, 3-5 tons of DNA can be utilized for several applications. Therefore, the utilization of the bio-based material is expected not only to reduce their undesired impacts to environment, but also to contribute to economic development [10-12].

In normal physiological state, DNA is not suitable for use as absorbent due to its water solubility. Therefore, DNA should be immobilized in the insoluble gels, which can be used as sensors or adsorbents of carcinogens $[8,13,14]$. DNA immobilization may be obtained by chemical and radiation crosslinking, gelation or complexation with metal salts. Gamma radiation has been proven to be an effective tool to introduce the crosslinking networks in polymer matrix for a long time. Even several degradation-type

\footnotetext{
*tmq $71 @$ yahoo.com
} 
polymers can crosslink by gamma irradiation in the presence of crosslinking agents such as trimethylallyl isocyanurate (TMAIC), triallyl isocyanurate (TAIC), epichlorohydrin (ECH) $[15,16]$.

Because DNA is easily damaged or broken to the DNA fragments by radiation at low radiation dose [4], and then the DNA gels could not be formed by radiation crosslinking. However, the DNA complex gels were prepared by gamma radiation in the presence of N,N'-methylenebisacrylamide (MBAA) [17]. DNA can also immobilize the crosslinking networks of polymers without using crosslinker [18].

In this study, the bovine serum albumin (BSA) and DNA/BSA complex gels were prepared by gamma irradiation of different DNA containing BSA solutions. Gel behaviors of the resulting gels were investigated by radiation dose and DNA content. The DNA/BSA complex gels were also studied as adsorbent for $\mathrm{AO}$, a model carcinogen. Adsorption kinetics of the complex gels were investigated with time and their adsorption capacity at equilibrium were determined.

\section{EXPERIMENTAL}

\subsection{Materials}

Bovine serum albumin (BSA) with a molecular weight of $66 \mathrm{kDA}$ and salmon DNA of about $10 \mathrm{kbp}$, corresponding to a molecular weight of $6 \mathrm{MDa}$ were purchased from ICN Biomedicals Inc. and Nippon Chemical Feeds Co., Ltd. Acridine Orange (AO) and other chemicals were bought from Wako Pure Chemicals.

\subsection{Preparation of DNA/BSA complex gels}

BSA was dissolved in distilled water, then various amounts of DNA were added to prepare the mixture solutions containing 10\% BSA and 0.2 to 2.0 wt.\% DNA, respectively. $1 \mathrm{~mL}$ of each solution was transferred to $2.0 \mathrm{~mL}$ microcentrigugal tube, centrifuged at $10.000 \mathrm{rpm}$ for $15 \mathrm{~min}$, degassed and irradiated at room temperature in order to prepare the BSA/DNA complex gels. BSA solution was also irradiated for prepare the BSA gel as control. Gels were obtained by gamma irradiation with dose of 10-160 $\mathrm{kGy}$ at the same dose rate of $10 \mathrm{kGy}$ per hour. Resulting gels were washed, immersed in MilliQ water for $48 \mathrm{~h}$ to remove soluble non-crosslinking components and the crosslinking gels were freeze-dried, weighted and stored for further experiments

\subsection{Gel behavior}

In this experiment, the BSA/DNA gels obtained by radiation crosslinking were analyzed by DNA content and radiation dose. Their gel fractions were measured by the following equation:

$$
G_{f}=\frac{W_{g}}{W_{i}} \times 100
$$

where $\mathrm{W}_{\mathrm{g}}$ is the dried weight of the crosslinking gel and $\mathrm{W}_{\mathrm{i}}$ is the total weight of BSA and DNA in the initial solution.
The dried crosslinking gel was immersed in distilled water to reach the equilibrium swelling, and its swelling degree was determined as follows:

$$
D_{s}=\frac{W_{s}-W_{g}}{W_{g}}
$$

where $\mathrm{W}_{\mathrm{g}}$ and $\mathrm{W}_{\mathrm{s}}$ are the weights of the dried gels before and after swelling, respectively.

\subsection{Measurement of $A O$ adsorption}

The AO solutions of different concentrations were prepared in the distilled water and their absorbance (ABS) was measured at $495 \mathrm{~nm}$ at room temperature $\left(25^{\circ} \mathrm{C}\right)$ using a UV-Vis spectrophotometer (Shimadzu, Japan) for making a calibration curve.

$0.05 \mathrm{~g}$ of the dried gel was immersed in $10 \mathrm{~mL}$ of a $15 \mu \mathrm{g} / \mathrm{mL}$ AO solution for adsorption. After a certain periods of adsorption, about $3.5 \mathrm{~mL}$ of the adsorbed solution was transferred to a quartz cell for $\mathrm{ABS}$ measurement and $\mathrm{AO}$ concentration ( $\left.\mathrm{C}_{\mathrm{AO}}\right)$ was calculated from the $\mathrm{AO}$ calibration curve. $\mathrm{AO}$ adsorption capacities of the gels were determined as differences in $\mathrm{AO}$ concentrations before $\left(\mathrm{C}_{0}\right)$ and after $\left(\mathrm{C}_{\mathrm{AO}}\right)$ immerging the gel in the initial $\mathrm{AO}$ solution at each time.

To estimate the adsorption capacity at equilibrium, the gel was submersed in AO solution for 4 days to reach the equilibrium, ABS of the adsorbed solution was measured, and then weight of $\mathrm{AO}$ adsorbed on the gel at equilibrium adsorption (Q $\left.\mathrm{Q}_{\mathrm{AO}}\right)$ was estimated as follows:

$$
Q_{A O}=\left(C_{0}-C_{A O}\right) \frac{V_{A O}}{m}
$$

Here, QAO is the weight ( $\mathrm{g}$ ) of $\mathrm{AO}$ adsorbed on $1 \mathrm{~g}$ dried gel at equilibrium. $\mathrm{C}_{\mathrm{O}}$ and $\mathrm{C}_{\mathrm{AO}}$ are the concentrations of $\mathrm{AO}$ initially and in equilibrium, respectively. $\mathrm{V}_{\mathrm{AO}}$ is the volume of $\mathrm{AO}$ in $\mathrm{mL}$, and $\mathrm{m}$ is the weight of the gel when dried.

\section{RESUlTS AND Discussions}

\subsection{Characteristics of the DNA/BSA complex gels}

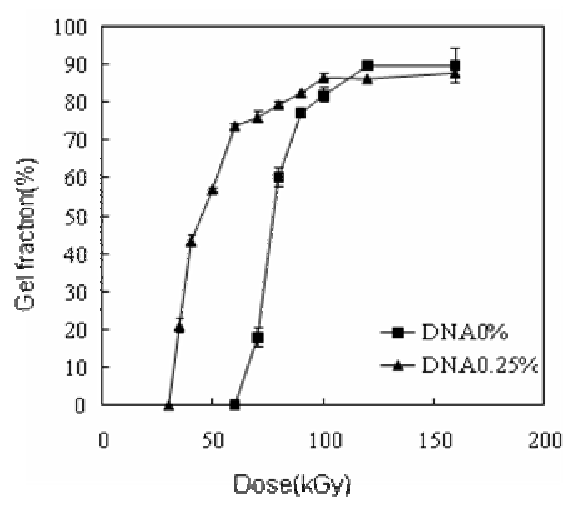

Figure1. Gel fraction of the BSA and DNA/BSA samples as functions of radiation dose 
As can be observed from Figure 1, the insoluble crosslinking gels are created by gamma irradiation, and gel fraction increased with radiation dose regardless of presence or absence of DNA. However, the gelation dose was reduced by adding $0.25 \%$ DNA. This may be due to the fact that BSA is a radiation crosslinking-type protein, and DNA can intercalate to the crosslinking network [18]. In addition, the complex gels can be formed by electrostatic interaction between positively charged BSA and negatively charged DNA [21].

In fact, DNA has been complexed to protein as reported by Kaya et al [22]. Large polyelectrolyte DNA was protected in the crosslinking network of small globular BSA protein, formed by gamma radiation. The structure of the complex gels did not further induce DNA breaks.

Fig. 1 also indicates that gel fraction seemed to saturate at doses higher than $100 \mathrm{kGy}$, and maximum values of gel fraction were about $80-90 \%$ since a part of the polymers could not be crosslinked. This result suggests that $100 \mathrm{kGy}$ is the optimal dose for the preparation of the DNA/BSA complex gel by gamma irradiation.

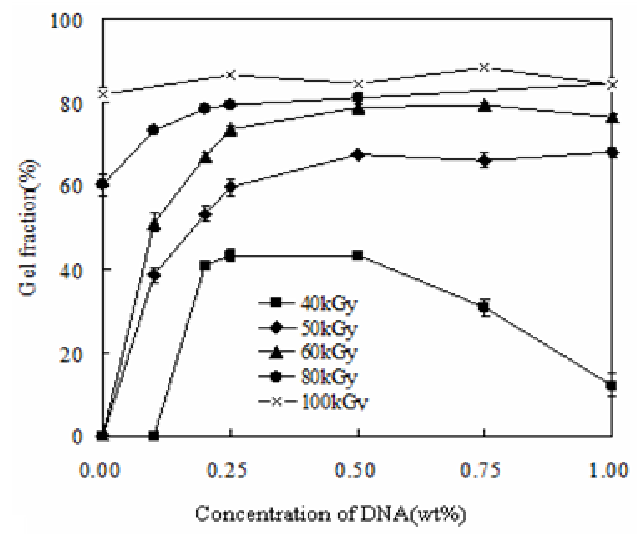

Figure 2. Gel fraction of the DNA/BSA complex gels by radiation versus DNA concentration

The gelation or radiation crosslinking also depended on DNA content in initial DNA/BSA mixture (see Fig. 2). With gamma radiation at $40 \mathrm{kGy}$, maximum gel fraction was obtained with the mixtures containing DNA of about $0.25-0.5 \%$. Gel fraction increased together with DNA content at doses higher than $50 \mathrm{kGy}$. The results also confirmed that gel fraction increased with radiation dose and the maximum values of gel fraction obtained by gamma irradiation at $100 \mathrm{kGy}$.

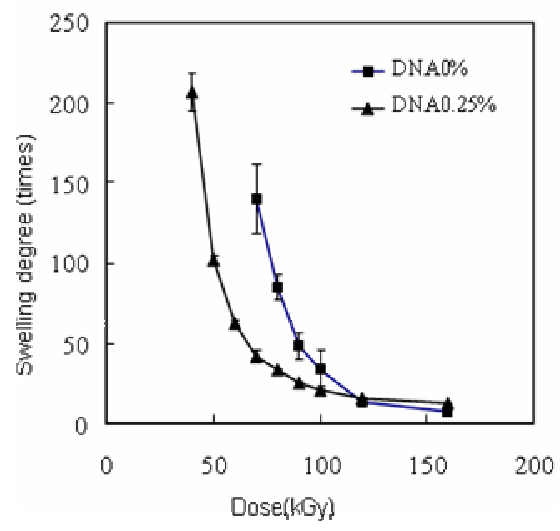

Figure 3. Swelling of the complex gel with radiation dose

The DNA/BSA complex gels were characterized by their swelling behaviors and the results were presented in the Figures 3 and 4. Similar to other radiation crosslinking gels, the swelling of the complex gels prepared from the same DNA/BSA mixture quickly reduced with the increase of radiation dose. The higher the radiation dose, the larger the number of radicals produced. As a result, the crosslinking networks become stronger, hindering the mobility of water or other solutes. The results also suggested that the presence of DNA in the complex gels greatly reduced their swelling degree. And the swelling degrees of both BSA and DNA/BSA complex gels prepared by irradiation with doses higher than 120 kGy are the same. However, the swelling degree of the complex gels prepared at the same radiation dose increased with DNA content; namely, that DNA may affect the crosslinking of proteins though it will not be broken by gamma irradiation as mentioned somewhere [23].

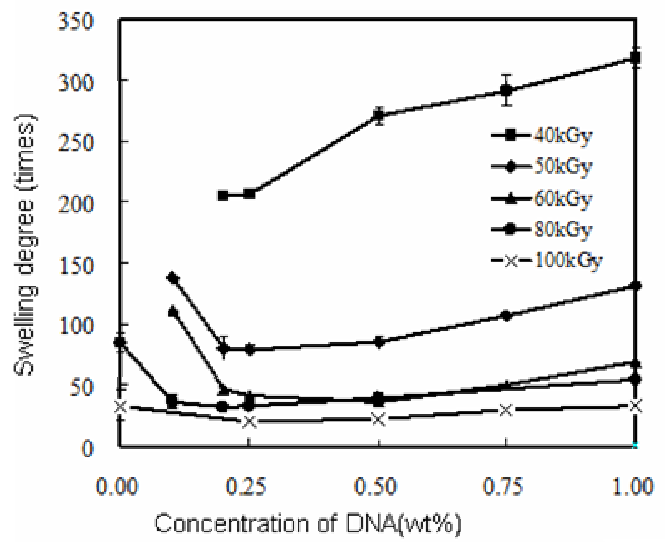

Figure 4. Swelling of the complex gels with DNA content

The swelling of the complex gels prepared by gamma irradiation at $100 \mathrm{kGy}$ was also investigated in relation to time to estimate the swelling degree at equilibrium. It is clear that swelling is a timedependent process. At the same time, the swelling degree of the gel increased with DNA content, and the time to reach the equilibrium swelling was longer by adding and increasing DNA content.

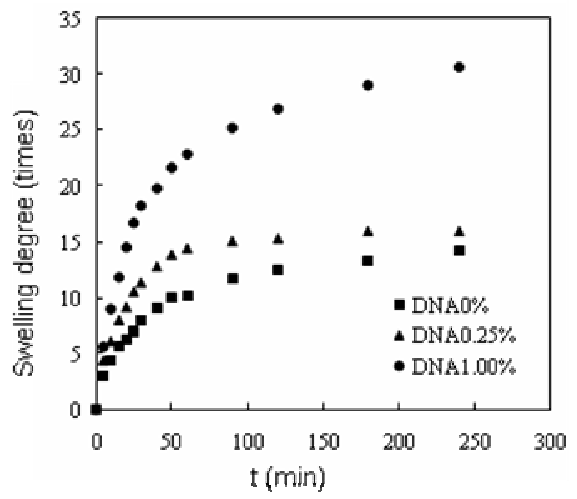

Figure 5. Swelling degree of the gels prepared by irradiation at $100 \mathrm{kGy}$ with time. 


\subsection{Adsorption measurement}

Absorbances of the AO solutions with concentration ranging from 5 to $20 \mu \mathrm{g} / \mathrm{mL}$ were measured. The data were fitted to a straight line equation as presented in Fig. 6. From the calibration curve, AO concentration in $\mu \mathrm{g} / \mathrm{mL}\left(\mathrm{C}_{\mathrm{AO}}\right)$ can be calculated from its absorbance as follow:

$C_{A O}=13.64 \times A B S$

(4)

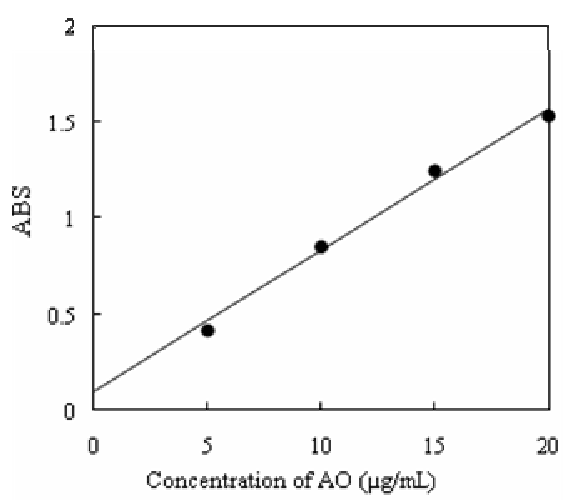

Figure 6. Calibration curve of acridine orange

AO was adsorbed to the DNA/BSA complex gels by its interaction with DNA and BSA. The AO adsorption of DNA/BSA gel was time-dependent. Figure 7 shows the $\mathrm{AO}$ adsorption of the complex gels obtained by gamma irradiation at $100 \mathrm{kGy}$ with adsorption time. It is obvious that $\mathrm{AO}$ adsorption increased with adsorption time. These results also indicate the concentration of AO that adsorbed to the gels increased with DNA content at the same adsorption time.

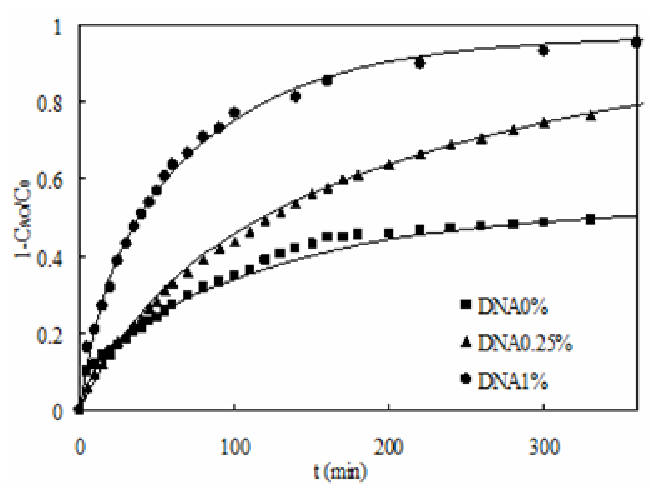

Figure 7. Time-dependent adsorption of AO to the complex gel prepared by gamma irradiation at $100 \mathrm{kGy}$

AO adsorptions were tried to fit by single or doubleexponential models. Using the systematic errors, the data seemed to fit in double exponential formula, which has been applied to describe the two-step adsorption process of rapidly and slowly adsorbed fractions $[18,20]$ as following:

$$
1-\left(\frac{C_{A O}}{C_{0}}\right)=a\left(1-\exp \left(\frac{-t}{\tau_{1}}\right)\right)+b\left(1-\exp \left(\frac{-t}{\tau_{2}}\right)\right)(5)
$$

Here, $\mathrm{t}$ is adsorption time; $\tau 1, \tau 2$ are the time constants of each fraction; and $\mathrm{a}, \mathrm{b}$ are the exponential factors.
The time required for adsorbate-adsorbent system reach adsorption equilibrium depends on the rate and characteristics of adsorbate and adsorbent. In this experiment, the gel was submerged in AO solution for a week to reach equilibrium and adsorption capacity of $\mathrm{AO}$ on the DNA/BSA complex gel was described as a function of time.

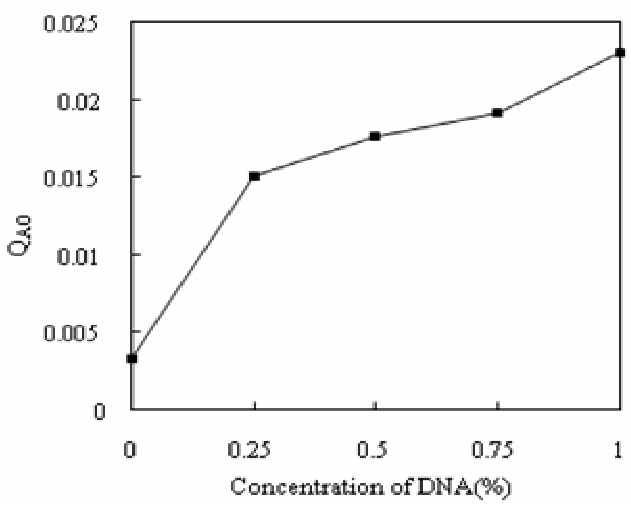

Figure 8. Dependence of AO adsorption on DNA content in the complex gels

Influence of DNA on the adsorption process has been investigated with the DNA/BSA complex gels obtained by gamma irradiation at $100 \mathrm{kGy}$. Figure 8 showed dependence of the adsorbed AO on DNA amount in the gels. The results revealed that the weight of $\mathrm{AO}$ adsorbed on the gel $\left(\mathrm{Q}_{\mathrm{AO}}\right)$ was rapidly increased by the presence of DNA and it also increased with DNA concentration.

\section{CONCLUSION}

DNA/BSA complex gels were successfully prepared from $10 \%$ BSA solution in the absence and presence of different concentrations of DNA by gamma irradiation. And the gels were characterized by gel behavior for utilization as absorbent for AO. Gel fraction of the complex gel seemed not to depend on the DNA content, but it increased with radiation dose. The presence of DNA greatly reduced the gelation dose. Gel fraction of the DNA/BSA complex gel becomes saturated at doses higher than $100 \mathrm{kGy}$, whereas its swelling degree reduces. The swelling of the complex gels obtained by gamma irradiation at $100 \mathrm{kGy}$ is a time-dependent process, and the swelling degree and the time required to reach the equilibrium swelling increased with DNA content.

The complex gels can be used as absorbent for $\mathrm{AO}$, and the adsorption capacity of AO to the DNA/BSA gels increased with time and DNA content. At the same radiation dose of $100 \mathrm{kGy}$, the weight of $\mathrm{AO}$ adsorbed to the complex gel also increased with DNA content.

Acknowledgement: The authors would like to thank Prof. Toshiaki Dobashi for all of his encouragement and support. 


\section{REFERENCES}

1. S.E. Manahan, "Organic Functional Groups and Classes of Organic Compounds," in Fundamentals of Environmental Chemistry, 3rd ed., Boca Raton (FL), USA: CRC Press, 2011, ch. 9, sec. 3, pp. 318-331.

2. H. Kitamura, C. Iwamoto, N. Sakairi, S. Tokura and N. Nishi, Marked Effect of DNA on Collagen Fibrillogenesis in Vitro, Int. J. Biol. Macromol., vol. 20, no.3, pp. 241-244, 1997

3. M. Yamada et al., UV-Irradiation-Induced DNA Immobilization and Functional Utilization of DNA on Nonwoven Cellulose Fabric, Biomaterials, vol. 22, no. 23, pp. 3121-3126, 2001

4. D.H. Van et al., "Study on DNA Damages Induced by UV Radiation,” Nucl. Sci. Technol., vol. 5, no. 4, pp. 1622, 2015

5. B.N. Ames, "Identifying Environmental Chemicals Causing Mutations and Cancer," Science, vol. 204, no. 4393, pp. 587-593, May 1979

6. D. Voet, J.G. Voet and C.W. Pratt, in Fundamentals of Biochemistry, 2nd ed., Hoboken (NJ), USA: Wiley, 2006, pp. 206-232

7. K. Furusawa, M. Wakamatsu, T. Dobashi and T. Yamamoto, "Adsorption Kinetics of Carcinogens to DNA Liquid Crystalline Gel Beads, Langmuir," vol. 23, no. 20, pp. 10081-10087, Aug. 2007

8. M. Yamada, K. Kato, M. Nomizu, K. Ohkawa, H. Yamamoto, N. Nishi, "UV-Irradiated DNA Matrixes Selectively Bind Endocrine Disruptors with a Planar Structure," Environ. Sci. Technol., vol. 36, no. 5, pp. 949-954, 2002

9. P.D. Don, Vietnam Environment Administration Magazine, Ministry of Natural Resource and Environment, 6-2014

10. K. Jayathilakan, K. Sultana, K. Radhakrishna and A.S. Bawa, "Utilization of Byproducts and Waste Materials from Meat, Poultry and Fish Processing Industries: a review," J. Food Sci. Technol., vol. 49, no. 3, pp. 278293, 2012

11. 西 則雄, 山田 真路, 劉向東, 污染物質除去材としてのDNA, vol. 52, no. 3, pp. 134137, 2003. (N. Nishi, Y. Shinro and M. Liu, "DNA as a Functional Material to Remove Environmental Pollutants," Kobunshi Gakkai, vol. 52, no. 3, pp. 134137, 2003)

12. H. Kitamura, E. Matsuura, A. Nagata, N. Sakairi, S. Tokura and N. Nishi, "DNA-Alginate Complex Recognized by Autoantibodies Against DNA,” Int. J. Biol. Macromol., vol. 20, no. 1, pp. 75-77, Feb. 1997
13. T. Dobashi, K. Furusawa, E. Kita, Y. Minamisawa and T. Yamamoto, "DNA Liquid-Crystalline Gel as Adsorbent of Carcinogenic Agent," Langmuir, vol. 23, no. 3, pp. 1303-1306, 2007

14. D. Umeno, T. Kano and M. Maeda, "Affinity Adsorption Separation of Mutagenic Molecules by Polyacrylamide Hydrogels Comprising Double-Stranded DNA," Anal. Chim. Acta., vol. 365, no. 1-3, pp. 101-108, June 1998

15. H. Mitomo, A. Kaneda, T.M. Quynh, N. Nagasawa and F. Yoshii, "Improvement of Heat Stability of Poly(LLactic Acid) by Radiation-Induced Crosslinking," Polymer, vol. 46, no. 13, pp. 4695-4703, June 2005

16. T.M. Quynh, H.H. Mai and P.N. Lan, "Stereocomplexation of Low Molecular Weight Poly(L-Lactic Acid) and High Molecular Weight Poly(D-Lactic Acid), Radiation Crosslinking PLLA/PDLA Stereocomplexes and their Characterization," Rad. Phys. Chem., vol. 83, pp. 105-110, Feb. 2013

17. Y. Maki, Y. Harigane and T. Dobashi, "Adsorption of Acridine Orange to DNA-Polyelectrolyte Complex Gels," Trans. Mater. Res. Soc. Jap., vol. 35, no. 4, pp. 873876,2010

18. K. Furusawa, E. Kita, T. Saheki, N. Nagasawa, N. Nishi and T. Dobashi, "Carcinogen Adsorbent Prepared from DNA Complex by Gamma-Ray Irradiation," $J$. Biomater. Sci., vol. 19, no. 19, pp. 1159-1170, 2008

19. J. Olejniczak, J. Rosiak and A. Charlesby, "Gel/Dose Curves for Polymers Undergoing Simultaneous Crosslinking and Scission," Int. J. Rad. Appl. Instr. C: Rad. Phys. Chem., vol. 37, no. 3, pp. 499-504, 1991

20. A. Wilczak and T.M. Keinath, "Kinetics of Sorption and Desorption of Copper(II) and Lead(II) on Activated Carbon," Water Envir. Res., vol. 65, no. 3, pp. 238244, May-June, 1993

21. H. Schuessler and E. Jung, "Protein-DNA Crosslinks Induced by Primary and Secondary Radicals," Int. J. Radiat. Biol., vol. 56, no. 4, pp. 423-435, 1989

22. M. Kaya et al., "Effect of DNA Structure on the Formation of Collagen-DNA Complex," Int. J. Biol. Macromol., vol. 35, no. 1-2, pp. 39-46, Mar. 2005

23. S. Gebicki and J.M. Gebicki, "Crosslinking of DNA and Proteins Induced by Protein Hydroperoxides," Biochem. J., vol. 338, no. 3, pp. 629-636, Mar. 1999 